Angela Pyle, $\mathrm{PhD}^{*}$

Helen J. Nightingale,

MBChB*

Helen Griffin, PhD

Angela Abicht, MD

Janbernd Kirschner, MD

Ivo Baric, MD

Mario Cuk, MD

Konstantinos Douroudis, $\mathrm{PhD}$

Lea Feder

Markus Kratz, MD

Birgit Czermin, PhD

Stephanie Kleinle, $\mathrm{PhD}$

Mauro Santibanez-Koref, MD

Veronika Karcagi, $\mathrm{PhD}$

Elke Holinski-Feder, $\mathrm{MD}, \mathrm{PhD}$

Patrick F. Chinnery, PhD, FRCP, FMedSci

Rita Horvath, MD, PhD

Correspondence to

Dr. Horvath:

rita.horvath@ncl.ac.uk

\section{Supplemental data} at Neurology.org/ng

\title{
Respiratory chain deficiency in nonmitochondrial disease
}

\section{OPEN}

\section{ABSTRACT}

Objective: In this study, we report 5 patients with heterogeneous phenotypes and biochemical evidence of respiratory chain (RC) deficiency; however, the molecular diagnosis is not mitochondrial disease.

Methods: The reported patients were identified from a cohort of 60 patients in whom RC enzyme deficiency suggested mitochondrial disease and underwent whole-exome sequencing.

Results: Five patients had disease-causing variants in nonmitochondrial disease genes ORAl1, CAPN3, COLQ, EXOSC8, and AN010, which would have been missed on targeted nextgeneration panels or on MitoExome analysis.

Conclusions: Our data demonstrate that RC abnormalities may be secondary to various cellular processes, including calcium metabolism, neuromuscular transmission, and abnormal messenger RNA degradation. Neurol Genet 2015;1:e6; doi: 10.1212/NXG.0000000000000006

\section{GLOSSARY}

ARE $=$ AU-rich element; $\mathbf{C o Q}_{10}=$ coenzyme $Q_{10} ;$ LGMD2A = limb-girdle muscular dystrophy type $2 \mathrm{~A} ; \mathbf{m R N A}=$ messenger $\mathrm{RNA} ; \boldsymbol{m t D N A}=$ mitochondrial DNA; $\mathbf{R C}=$ respiratory chain.

Respiratory chain (RC) complex defects are hallmarks of mitochondrial disease that often provide the first diagnostic evidence for a mitochondrial disorder and guide subsequent DNA analysis of the mitochondrial DNA (mtDNA) and nuclear genes encoding mitochondrial proteins. ${ }^{1}$ In a substantial proportion of cases, it is not possible to reach a molecular diagnosis, and it is assumed that most of these patients carry undetected mutations in genes coding for mitochondrial proteins. This report presents 5 patients with heterogeneous phenotypes and biochemical features of RC deficiency; however, the molecular diagnosis is not mitochondrial disease.

METHODS Patients with biochemical evidence of RC deficiencies measured by standard methods in accredited laboratories in whom mtDNA mutations had been excluded were selected from a cohort of 60 patients for whole-exome sequencing. ${ }^{1}$ The diagnosis of a mitochondrial RC deficiency was based on the recently published consensus paper by the Mitochondrial Medicine Society (USA). ${ }^{2}$ Coverage and depth statistics of exome sequencing for each patient and the bioinformatic prediction for each mutation are listed in tables e-1 and e-2 at Neurology.org/ng.

Standard protocol approvals, registrations, and patient consents. Informed consent was obtained from all participants in accordance with protocols approved by local institutions and research ethics committees.

RESULTS Patient 1 presented with generalized muscular hypotonia, failure to thrive, liver dysfunction, atrial septal defect, and severe immunodeficiency. Based on the biochemical defect of complex I (50\%) and IV (80\% rest-activity) in skeletal muscle, mitochondrial disease was suggested. Exome sequencing identified a homozygous mutation c.587T $>$ C, p.Leu196Pro in the ORAI1 gene, which is predicted to be deleterious with 6 different prediction programs (table e-2) and is located next to a pathogenic mutation (p.Leu194Pro). ${ }^{3}$ ORAII

\footnotetext{
*These authors contributed equally to this work.

From the Wellcome Trust Centre for Mitochondrial Research (A.P., H.J.N., H.G., K.D., M.S.-K., P.F.C., R.H.), Institute of Genetic Medicine, Newcastle University, Newcastle upon Tyne, United Kingdom; Medical Genetics Center (A.A., L.F., B.C., S.K., E.H.-F.), Munich, Germany; Division of Neuropediatrics and Muscle Disorders (J.K.), University Medical Center, Freiburg, Germany; Department of Paediatrics (I.B., M.C.), University Hospital Center Zagreb \& University of Zagreb, School of Medicine, Zagreb, Croatia; Department of Paediatrics (M.K.), Hospital Baden-Baden, Germany; and Department of Molecular Genetics and Diagnostics (V.K.), NIEH, Budapest, Hungary.

Funding information and disclosures are provided at the end of the article. Go to Neurology.org/ng for full disclosure forms. The Article Processing Charge was paid by Wellcome Trust Funding.

This is an open access article distributed under the Creative Commons Attribution License, which permits unrestricted use, distribution, and reproduction in any medium, provided the original work is properly cited.
} 
Figure Detailed clinical and molecular genetic characteristics of patients in this study and localization of nuclear mutant proteins resulting in respiratory chain deficiencies

A

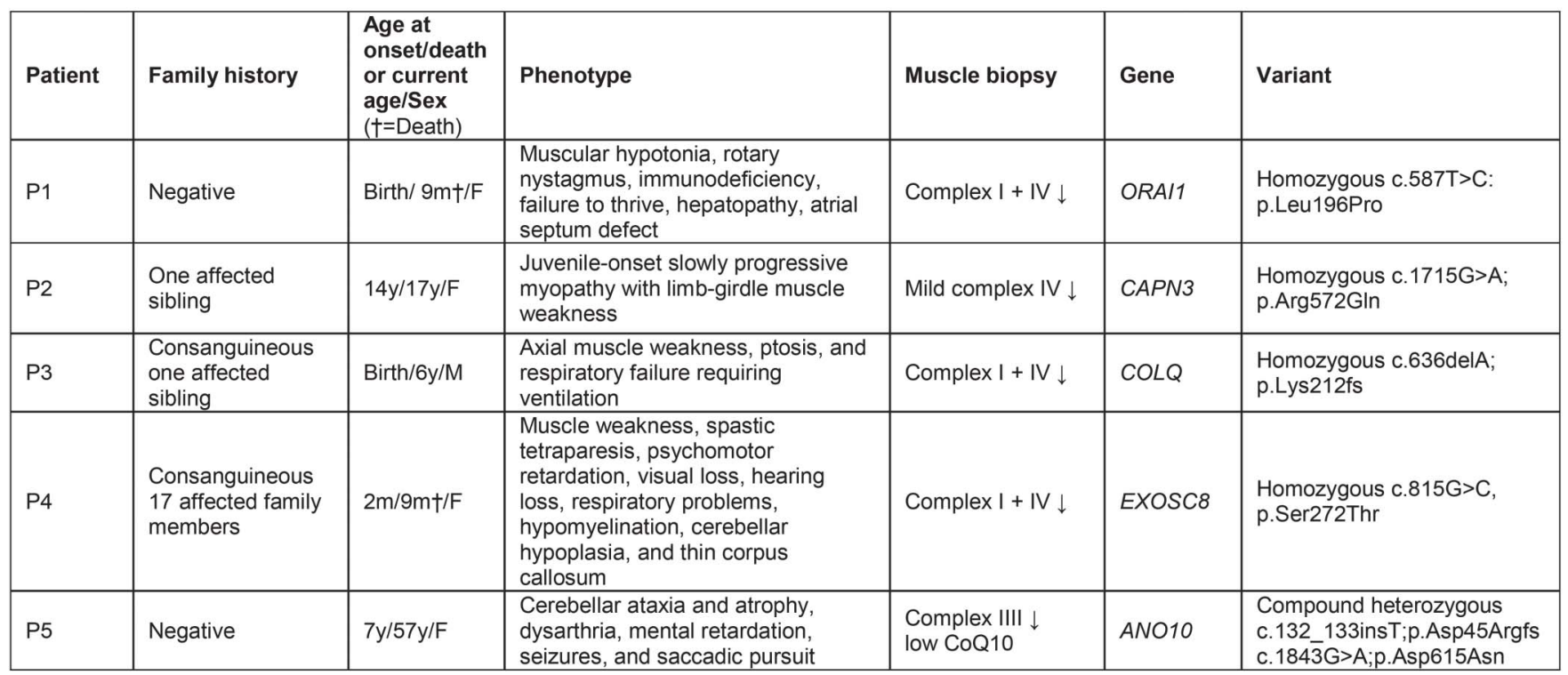

B

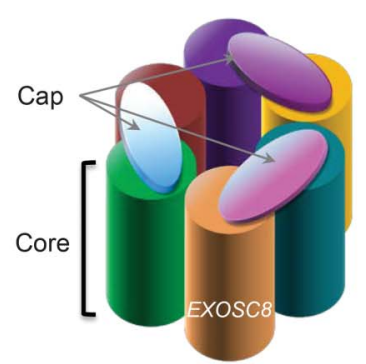

EXOSC8

Human exosome protein

RNA metabolism
P4

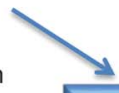

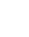

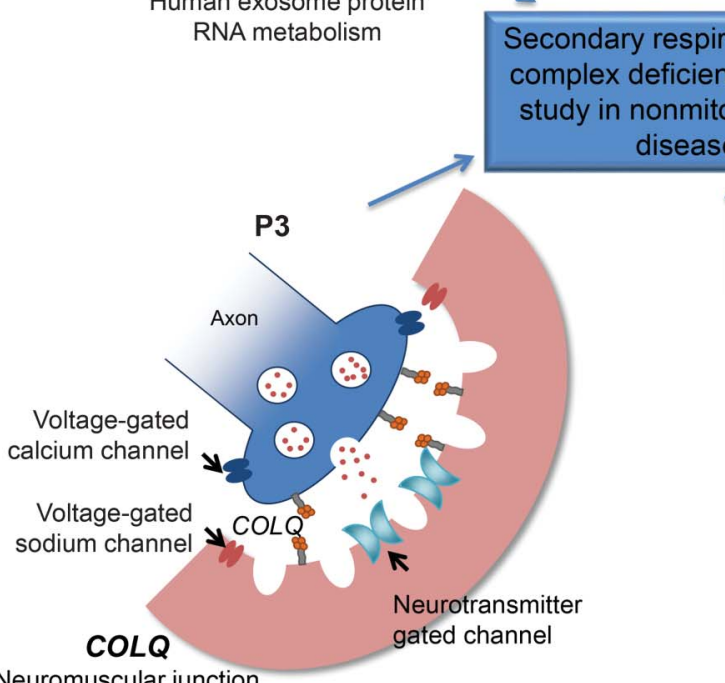

Neuromuscular junction gated channel

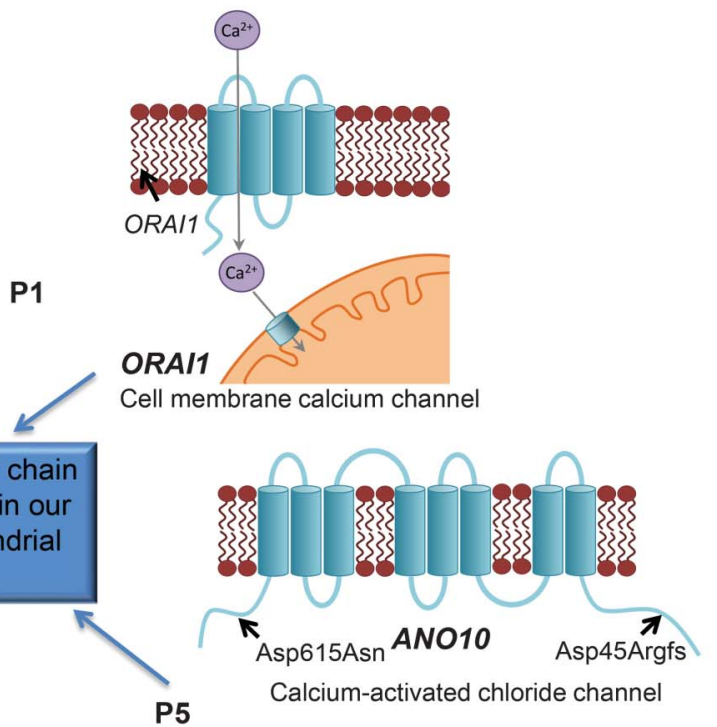

P2

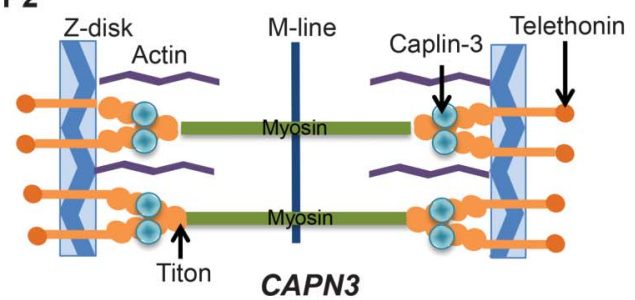

Calcium-activated muscle protease

(A) Table of clinical and molecular genetic characteristics of 5 patients with heterogeneous phenotypes and biochemical features of respiratory chain deficiency. (B) Crystal structure of the human exosome complex involved in RNA metabolism. EXOSC8 highlighted in pink. ORAI1, calcium channel located on the cell membrane. ANO10, calcium-activated chloride channel located on the cell membrane. CAPN3, an intracellular calcium-activated neutral protease isoform located within the sarcomere. COLQ protein, a collagen-like subunit associated with acetylcholinesterase in skeletal muscle. $C_{0} Q_{10}=\operatorname{coenzyme~}_{10}$.

encodes a calcium release-activated calcium channel protein that allows cellular calcium influx $x^{3}$ and may alter mitochondrial calcium metabolism, leading to
RC deficiency. Autosomal recessive mutations in ORAI1 have previously been described in association with severe combined immunodeficiency and 
congenital myopathy and in dominantly inherited tubular aggregate myopathy with hypocalcemia. ${ }^{3}$

Patient 2 presented with a juvenile-onset slowly progressive myopathy and limb-girdle muscle weakness. The clinical diagnosis of a mitochondrial myopathy was based on the detection of cytochrome $c$ oxidase-negative fibers and decreased complex IV activity in muscle (80\% rest-activity). A known pathogenic homozygous c.1715G $>$ A, p.Arg572Gln mutation was detected in CAPN3 encoding a skeletal muscle-specific intracellular calcium-activated neutral protease, and its deficiency leads to oxidative stress and potentially a secondary RC deficiency. ${ }^{4}$ This is a previously published pathogenic mutation and the only variant that segregated with the disease in the family. CAPN3 mutations are common causes of limb-girdle muscular dystrophy type $2 \mathrm{~A}$ (LGMD2A). ${ }^{4}$ Muscle biopsy shows a dystrophic pattern; however, disorganized mitochondria and reduced complex $\mathrm{V}$ levels were occasionally reported in a few patients with LGMD2A. ${ }^{4}$

Patient 3 presented with axial muscle weakness, ptosis, respiratory failure requiring ventilation, and reduced IV (80\% rest-activity) and borderline complex I activities. We detected a homozygous frameshift mutation c.636delA, p.Lys212fs in the COLQ gene. Mutations of the acetylcholinesterase collagenlike tail subunit gene (COLQ) cause congenital myasthenic syndromes due to the deficiency of acetylcholine esterase at the synaptic endplate. ${ }^{5}$ The clinical phenotype includes hypotonia, muscle weakness, delayed motor development, ophthalmoparesis, and respiratory failure. No involvement of mitochondria has been suggested in previous patients to date. ${ }^{5}$

Patient 4 belonged to a large Hungarian Roma pedigree presenting with hypomyelination, hypoplasia of the cerebellum and corpus callosum, and spinal muscular atrophy. Muscle biopsy revealed reduced complex I (60\% rest-activity) and IV (80\% restactivity). We identified a homozygous c. $815 \mathrm{G}>\mathrm{C}$, p.Ser272Thr mutation in a novel disease gene EXOSC8 encoding an exosome subunit involved in AU-rich element (ARE)-containing messenger RNA (mRNA) degradation, and the altered myelination was due to abnormal degradation of ARE myelin proteins. ${ }^{6}$ The pathogenicity of the mutation was supported by the absence of EXOSC8 protein in myoblasts of the patient and by segregation with the disease in the large pedigree. ${ }^{6}$ A secondary RC defect in these patients may be related to abnormal degradation of ARE mRNAs of mitochondrial disease genes.

Patient 5 presented in childhood with epilepsy and learning difficulties and developed cerebellar ataxia, brisk reflexes, and nystagmus from age 45 years. Complex III defect (60\% rest-activity) and low coenzyme $\mathrm{Q}_{10}\left(\mathrm{CoQ}_{10}\right)$ (60\% of low normal) were detected in her muscle. We identified compound heterozygous pathogenic mutations in ANO1O (c.132_133insT, p.Asp45Arg fs*53 and c.1843G $>$ A, p.Asp615Asn). ${ }^{7}$ The pathogenicity of the missense variant c.1843G $>$ A, p.Asp615Asn has been confirmed by its detection in additional patients. ${ }^{8} \mathrm{CoQ}_{10}$ supplementation resulted in clinical improvement, emphasizing the importance of low $\mathrm{CoQ}_{10}$ in the pathomechanism. ${ }^{7}$ ANO1O encodes an anoctamin protein forming calcium-activated chloride channels, implying that an abnormal calcium metabolism may cause mitochondrial dysfunction in ANO10 deficiency. ${ }^{7}$

DISCUSSION Typically, RC defects are associated with mutations in the mtDNA or in nuclear genes affecting mitochondrial proteins. The patients we present here had disease-causing (previously reported or nonsense) variants in nonmitochondrial disease genes, which would have been missed on targeted next-generation panels or on MitoExome analysis. ${ }^{9}$ Our data demonstrate that RC abnormalities may be secondary to various cellular processes, including calcium metabolism, neuromuscular transmission, and abnormal mRNA degradation; however, the role of mitochondria in these diseases needs further investigation (figure). Secondary RC defects in patients with neurogenetic disease have previously been reported. For example, Alexander disease is caused by nuclear mutations encoding non-RC chain proteins, but patients exhibit biochemical and MRI findings typically found with RC abnormalities. ${ }^{10}$

Faced with increasing numbers of published disease-causing variants, improved and more accessible sequencing techniques, and more comprehensive phenotype characterization, the clinician should keep an open mind when approaching genetic testing and not limit testing to predicted disease-causing variants in suspicion of mitochondrial disease.

\section{AUTHOR CONTRIBUTIONS}

Dr. A.P.: study concept and design, acquisition of data, and drafting of the manuscript. Dr. H.J.N.: study concept and design, acquisition of data, and drafting of the manuscript. Dr. H.G.: analysis and interpretation. Dr. A.A.: critical revision of the manuscript for important intellectual content. Dr. J.K.: acquisition of data. Prof. I.B.: acquisition of data. Dr. M.C.: acquisition of data. Dr. K.D.: analysis and interpretation. Ms. L.F.: analysis and interpretation. Dr. M.K.: acquisition of data. Dr. B.C.: acquisition of data. Dr. S.K.: acquisition of data. Dr. M.S.-K.: interpretation of data. Dr. V.K.: acquisition of data. Prof. E.H.-F.: critical revision of the manuscript for important intellectual content. Prof. P.F.C.: critical revision of the manuscript for important intellectual content. Prof. R.H.: study concept and design, acquisition of data, and drafting of the manuscript.

\section{STUDY FUNDING}

R.H. was supported by the Medical Research Council (United Kingdom) (G1000848) and the European Research Council (309548). P.F.C. is a Wellcome Trust Senior Fellow in Clinical Science and an NIHR Senior Investigator who also receives funding from the Medical Research Council (United Kingdom), the UK Parkinson's Disease Society, and the UK 
NIHR Biomedical Research Centre for Ageing and Age-related disease award to the Newcastle upon Tyne Foundation Hospitals NHS Trust.

\section{DISCLOSURE}

Dr. Pyle, Dr. Nightingale, Dr. Griffin, and Dr. Abicht report no disclosures. Dr. Kirschner has served on scientific advisory boards for PTC Therapeutics ISIS/Biogen Roche Pharma; has received funding for travel and/or speaker honoraria for ENMC workshop on neuromuscular diseases (nonprofit); has served as Associate Editor of the Orphanet Journal of Rare Diseases; and has received research support from the German Ministry of Research and Education European Union. Dr. Baric has received funding for travel and/or speaker honoraria from the Annual Multidisciplinary European Phenylketonuria Symposium; has served on the editorial board of Journal of Inherited Metabolic Disease; has served as prinicipal investigator in clinical trials sponsored by Synageva BioPharma; and has received research support from Ministry of Science, Education and Sports of Republic of Croatia and Innermed. Dr. Cuk, Dr. Douroudis, Ms. Feder, Dr. Kratz, Dr. Czermin, and Dr. Kleinle report no disclosures. Dr. Santibanez-Koref has received research support from Medical Research Council, The Leverhulme Trust, and Sir Jules Thorn Charitable Trust. Dr. Karcagi and Dr. Holinski-Feder report no disclosures. Dr. Chinnery has served on the editorial board of Brain and has received research support from the Medical Research Council (United Kingdom). Dr. Horvath has received funding from the Medical Research Council (United Kingdom) (G1000848), the European Research Council (309548), and from the Mitochondrial European Educational Training (MEET), ITN MARIE CURIE PEOPLE, (317433). Go to Neurology.org/ng for full disclosure forms.

Received March 3, 2015. Accepted in final form April 7, 2015.

\section{REFERENCES}

1. Taylor RW, Pyle A, Griffin H, et al. Use of whole-exome sequencing to determine the genetic basis of multiple mitochondrial respiratory chain complex deficiencies. JAMA 2014;312:68-77.
2. Parikh S, Goldstein A, Koenig MK, et al. Diagnosis and management of mitochondrial disease: a consensus statement from the Mitochondrial Medicine Society. Genet Med Epub 2014 Dec 11.

3. Feske S. CRAC channelopathies due to mutations in ORAI1 and STIM1. In: Ochs HD, Smith CIE, Puck JM, editors. Primary Immunodeficiency Diseases: A Molecular and Genetic Approach, 3rd ed: New York: Oxford University Press; 2013:279-285.

4. Nilsson MI, Macneil LG, Kitaoka Y, et al. Redox state and mitochondrial respiratory chain function in skeletal muscle of LGMD2A patients. PLoS One 2014;9: e102549.

5. Mihaylova V, Müller JS, Vilchez JJ, et al. Clinical and molecular genetic findings in COLQ-mutant congenital myasthenic syndromes. Brain 2008;131:747-759.

6. Boczonadi V, Muller JS, Pyle A, et al. EXOSC8 mutations alter mRNA metabolism and cause hypomyelination with spinal muscular atrophy and cerebellar hypoplasia. Nat Commun 2014;5:4287.

7. Balreira A, Boczonadi V, Barca E, et al. ANO10 mutations cause ataxia and coenzyme Q10 deficiency. J Neurol 2014; 261:2192-2198.

8. Renaud M, Anheim M, Kamsteeg EJ, et al. Autosomal recessive cerebellar ataxia type 3 due to ANO10 mutations: delineation and genotype-phenotype correlation study. JAMA Neurol 2014;71:1305-1310.

9. Calvo SE, Compton AG, Hershman SG, et al. Molecular diagnosis of infantile mitochondrial disease with targeted next-generation sequencing. Sci Transl Med 2012;4: 118 ral 10.

10. Caceres-Marzal C, Vaquerizo J, Galan E, Fernandez S. Early mitochondrial dysfunction in an infant with Alexander disease. Pediatr Neurol 2006;35:293-296. 


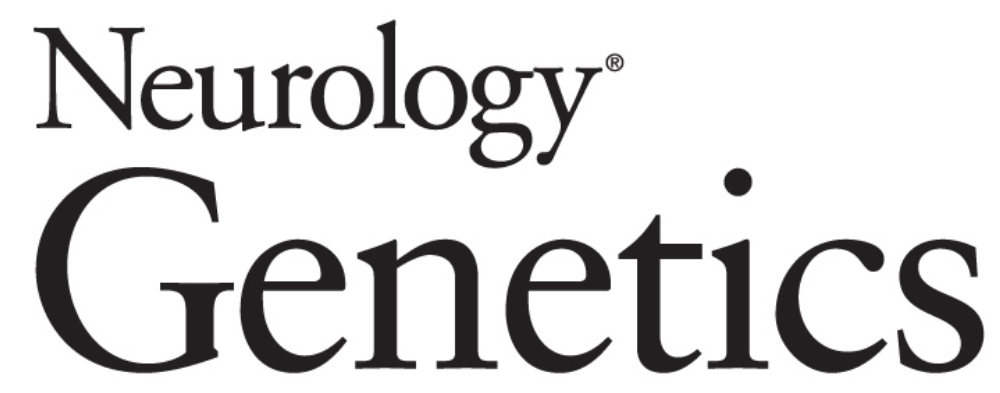

\section{Respiratory chain deficiency in nonmitochondrial disease Angela Pyle, Helen J. Nightingale, Helen Griffin, et al. Neurol Genet 2015;1; \\ DOI 10.1212/NXG.0000000000000006}

\section{This information is current as of April 27, 2015}

\section{Updated Information \& Services}

Supplementary Material

References

Citations

Permissions \& Licensing

Reprints including high resolution figures, can be found at: http://ng.neurology.org/content/1/1/e6.full.html

Supplementary material can be found at: http://ng.neurology.org/content/suppl/2015/04/27/1.1.e6.DC1

This article cites 8 articles, 0 of which you can access for free at: http://ng.neurology.org/content/1/1/e6.full.html\#\#ref-list-1

This article has been cited by 5 HighWire-hosted articles: http://ng.neurology.org/content/1/1/e6.full.html\#\#otherarticles

Information about reproducing this article in parts (figures,tables) or in its entirety can be found online at:

http://ng.neurology.org/misc/about.xhtml\#permissions

Information about ordering reprints can be found online: http://ng.neurology.org/misc/addir.xhtml\#reprintsus

Neurol Genet is an official journal of the American Academy of Neurology. Published since April 2015, it is an open-access, online-only, continuous publication journal. Copyright $(2015$ American Academy of Neurology. All rights reserved. Online ISSN: 2376-7839.

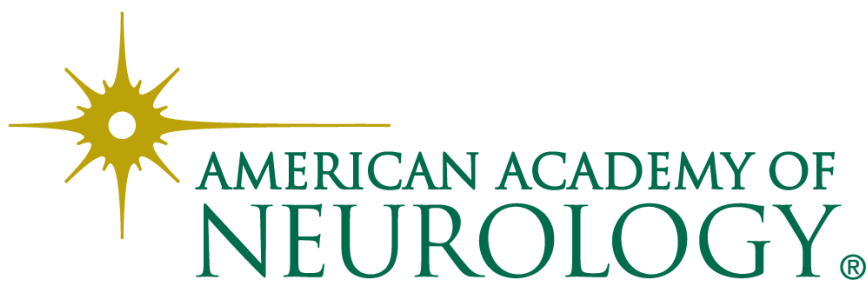

